\title{
Los contratos administrativos y el proceso de lesividad
}

I. LOS CONTRATOS ADMINISTRATIVOS Y EL PROCESO ADMINISTRATIVO

A) El párrafo primero del artículo $50^{\circ}$ del Texto refundido de la Ley de lo Contencioso-administrativo de 1952 (en lo sucesivo, citaré : L. C.), dice : "Continuarán, sin embargo, atribuídas a la jurisd:cción contencioso-administrativa las cuestiones referentes al cumplimiento, inteligencia, rescisión y efectos de los contratos celebrados por la Administración central, provincial y municipal para obras y servicios públicos de toda especie.n Este precepto.constituye la disposición fundamental acerca de la jurisdicción a la que corresponde conocer de las cuestiones derivadas de los contratos administrativos. Como en el mismo se señala claramente-y existe jurisprudencia re:terada acerca de cuándo un contrato es administrativo-corresponde su conocimiento a la jurisdicción contenciosoadministrativa.

B) Se ha justificado dicha norma en base a las siguientes razones (1):

1. Que para resolver las cuestiones derivadas de los contratos para obras y servicios públicos "debe tenerse siempre muy presente el interés público, y ni los Tribunales ordinarios deben re-

(1) En contra, siguiendo su conocida postura sobre la jurisdicción administrativa y su falta de fundamenfo, A. González, La materia contencioso-administrativa, Madrid, 1891, pág. 317. 
solver cuestiones entre el interés social y el particular, ni su organización les hace a propósito para hallar los medios de conectar aquel supremo interés con las justas exigencias de los contratistas, en tanto que los Tribunales administrativos, compuestos de personas conocedoras de las necesidades del servicio público y dotadas de aptitud y libertad suficientes, pueden evitar con determinaciones basadas en principios de equidad los irreparables agravios que se habrán de ocasionar con la aplicación severa del derecho estrictoi. En este sentido, Gallostra (2).

2. Que, como la Administración conserva en materia de contratos administrativos el privilegio de la acción de oficio, debe admitirse al particular la posibilidad de acudir a los órganos de la jurisdicción contencioso-administrativa para impugnar los actos que la Administración dicte, haciendo uso de aquel privilegio. La doctrina suele señalar cómo el Real Decreto de 27 de febrero de 1852 sentaba el principio de que la Administración no debe ser interrumpida cuando ocurriese la necesidad de obligar al contratista al cumplimiento de lo pactado, sin perjuicio de que éstos puedan recurrir en la vía contenciosa contra la providencia que lastima sus derechos (3).

C) Pero si es indudable que las cuestiones referentes a los contratos administrativos pueden ser conocidas por la jurisdicción contencioso - administrativa a través de un proceso administrativo normal (proceso en que el demandante es persona distinta de la entidad que dictó el acuerdo impugnado), se ha discutido si pueden ser planteadas a través de un proceso de lesividad. Este es el

(2) Lo contencioso-administrativo, Madrid, 1881.

(3) Cfr. Alfaro, Tratado completo de lo contencioso-administrativo, Madrid, 1875, pág. 88, y Abella, Tratado térico-práctico de lo contenciosaadministrativo, Madrid, 1888, pág. 202.

Sobre la doctrina general del principio de ejecutoriedad y su aplicación a los contratos administrativos, vid. Rodríguez Moro, La ejecutividad del acto administrativo, Madrid, 1949, pág. 126 y ss., en especial. Sobre la nueva reglamentación de la contratación administrativa local y el citado principio, vid. García de Enterría, Dos regulaciones orgánicas de la contratación administrativa, "Revista de Administración pública", núm. 10, pág. 279 y s. 
problema que se plantea-e intenta resolver-en el presente trabajo.

\section{Doctrinas QUe SE haN Formulado}

A) Doctrinas negativas.-Existe un primer grupo de autores que, en base a ciertas resoluciones de nuestro Tribunal Supremo, han afirmado la imposibilidad de que se impugnen por la Administración en vía contencioso-administrativa los contratos administrativos. La mayoría de los autores que defienden esta posición no se plantean el problema de la impugnabilidad; se limitan a recoger ciertas sentencias en que así se afirma.

1. Royo-Villanova (S.), por ejemplo (4), afirma que la jurisprudencia ha considerado que la declaración de lesividad se refiere a las resoluciones, no a los contratos; con relación a éstos, sóio cabe que los Ayuntamientos les rescindan o pidan su nulidad (sentencias de 29 de junio y. 10 de diciembre de 1934); por eso, no pueden declararse lesivos los acuerdos municipales que no tienen propiamente carácter de resolución, sino que en su esencia son la aceptación de una propuesta, el acto de consentimiento que vino a constituir un contrato (sentencia de 25 de marzo de 1941). En aná. logo sentido se había pronunciado Pi Suñer (5), y más tarde Gascón y Marín y Leira (6).

2. Es cierto que existe tal doctrina jurisprudencial, aunque en otras resoluciones se atenúa el principio. Teniendo en cuenta estas otras resoluciones, y refiriéndome a la doctrina jurisprudencial, en mi trabajo La declaración de lesividad (7), afirmaba : "La sentencia de 10 de diciembre de 1934, dice: En ningún caso, asł también lo ha declarado con repetición este Tribunal, puede declarar lesivos los contratos que celebre, y contra ellos le cabe ejer.

(4) Problemas del régimen jurídico municipal, Madrid, 1944, pág. 176.

(5) Lo contencioso-administrativo, Barcelona, 1927, pág. 161.

(6) Notas a Los contralos administrativos, de Fernández de Velasco. 2.: ed., Madrid, 1945, pág. 192.

(7) "Revista de Administración pública", núm. 2, pág. 68 y s. 
citar la acc:ón rescisoria o de nulidad que sea procedente en vía administrativa o en la contenc:osa ante la jurisdicción competente según la naturaleza del acto". $Y$, después, añadía en el citado trabajo: "Pero si un contrato administrativo no puede ser impugnado mediante la acción contenciosa de lesividad, sí puede serlo la resolución por la que se rescinde un contrato y se fija indemnización al contratista (sentencia de 3 de febrero de 1906) y los acuerdos por los que la Admin:stración decida acudir a una determinada forma de contratación administrativa (sentencias de 19 de marzo y 8 de mayo de 1936)". Por tanto, no tiene razón Guaita cuando en su obra El proceso adninistrativo de lesividad (8), me incluye, sin hacer salvedad alguna, entre los autores que adoptan una postura negativa ante el problema que estudiamos, ya que, en cierto modo, al señalar la posibilidad de que se impugnen los acuerdos por los que la Administración decide acudir a una forma de contratación ad. ministrativa, mantengo posic:ón análoga a la por él defendida (9).

(8) Barcelona, 1953, pág. 110.

(9) Pues, como luego vereḿos, señala que, "más que al contrato, lo que declara lesivo la Adiministración es su declaración de voluntad, es decir, el acto o acuerdo mediante el cual otorgó su consentimiento", lo cual es una consecuencia lógica del concepto y fundamento del proceso de lesividad. En efecto:

a) El proceso de lesividad es, como ha señalado reiterada jurisprudencia, un proceso de naturaleza excepcional, que supone una exrepción al principio de que nadie puede ir contra sus propios actos. Es decir, sempre parte de un acto de la misma parte demandante: trata de obtener la anulación de un acto de la entidad que inicia el proceso. Es el reverso del supuesto ordinario en que el acto de una entidad administrativa se impugna por persona distinta de la que dictó el acto.

b) Luego, para que exista un proceso de lesividad excepcional, el acto que ha de impugnarse ha de ser dictado por la propia entidad demandante. Si fuese un acto bilateral-en el que intervienen dos voJuntades-, no habria necesidad de acudir a un supuesto excepcional -como es el que conteripla el proceso de lesividad-, como no son suruestos de proceso civil excepcional aquellos en que se deduce una jretensión de nulidad de un contrato. No existe contravención al principio de los actos propios, ya que se impugna un acto formado por dos voluntades, por el autor de una de ellas.

c) Es decir, si se impugnara el contrato, no vemos la necesidad de que se acuda al proceso de lesividad, ni vemos razún para que la doc- 
B) Doctrinas positizas.-Existen, por el contrario, otros autores que, en base a otras resoluciones de nuestro Tribunal Supremo, afirman la posibilidad de que se impugnen ante la jurisdicción contencioso-administrativa los contratos sobre obras y servicios públicos mediante la pretensión de lesividad.

1. En esta dirección, podemos citar a Aivarez Gendín (10), Abella (11) y Albi (12). Este último, refiriéndose a la nulidad de los contratos administrativos, señala las dos direcciones seguidas por nuestra jurisprudencia sobre el problema:

a) Una, mantenida en sentencias de 16 de diciembre de 1900 y 25 de junio de 1907, que permite la declaración de nulidad he cha por la Administración, sin perjuicio de la posibilidad del particular de impugnar el acto declarando la nulidad ante los organos de la jurisdicción contencioso-administrativa. Según esta dirección, por tanto, la Administración no tendría necesidad alguna de acudir, como demandante, ante los órganos jurisdiccionales.

b) Otra, mantenida en sentencias de 3 y 10 de diciembre de 1896, 7 de marzo de 1901, 12 de febrero de 1910, 11 de diciembre de 1934 y 24 de octubre de 1942, según la cual las facultades de la Administración para rescindir con carácter ejecutivo los contratos administrativos no puede extenderse a la declaración de nulidad; si la Administración entiende que el contrato es nulo, debe solicitar la nulidad del Tribunal competente. $Y$ en ocasiones (sentencias 11 de diciembre de 1934, 28 de febrero y 23 de abril de 1935 y 11 de febrero y 24 de octubre de 1942) señala que debe declararse la nulidad precisamente a través de un proceso de lesividad. Concretamente, en la última de las sentencias citadas, se dice: "Que es principio sancionado por constante jurisprudencia que la Adminis-

trina (Albi y Guaita, por ejemplo), estimen imposible un proceso admiristrativo ordinario in ciado por la Administración. Pero, en realidad, como se dice en el texto-y luego insistiremos sobre este extrerno-, siempre se impugnan actos concretos de la Administración.

(10) La nueva Ley de Régimen Local, ReVISTA DE Estudios DE LA VIDA Local, núm. 58, pág. 553.

(11) Régimen local, Madrid, 1051, pág. 594 yy ss.

(12) Los contratos municipales, 1944, pág. 343 y ss. 
tración no puede volver sobre sus propios acuerdos, cuando son declaratorios de cierecho, saivo ei cáso de haber incurrido en errores materiales de hecho, claros y evidentes, estándola reservado, en otro supuesto, para evitar el perjuicio que a los intereses del Estado infieran sus propias resoluciones, la facultad de impugnarlas en vía contenciosa, previa declaración de lesividad... y habiéndose declarado derechos a favor de la Sociedad "R y $C$ " en ei concurso y acuerdos referentes a la adjudicación de las obras del nuevo Hospital, es evidente que el Ayuntamiento... no puede, por sí, anular tales resoluciones sin que, previa lesividad acordada de las mismas, resuelva acudir a la jurisdicción contenciosa para la revisión de ellas y declaración de nulidad si fuera procedenten.

Y Albi estima que esta es la solución correcta, por no existir "motivo alguno que aconseje una diferenciación entre las diversas resoluciones declaratorias de derechos, puesto que el artículo $2 .^{\circ} \mathrm{de}$ la Ley, al hablar de la declaración de lesividad, no discrimina entre las que sean de naturaleza contractual y las de otra clase, siendo principio constante de interpretación jurídica que donde la Ley no distingue no debe establecerse distinción" y porque "esa distinción no sería, en resumen, más que un juego de palabras, puesto que, dentro de las normas fijadas por la L. C., entre un contrato declarado lesivo o anulado sin declaración de lesividad, en la práctica no existiría diferencia alguna» (13).

2. Ultimamente ha sido Guaita el que, con brillantez indudable, ha defendido la tesis de la impugnabilidad mediante un proceso de lesividad de los contratos administrativos. $Y$ lo hace en base a los argumentos siguientes (14):

a) Que el artículo $5 .^{\circ}$, L. C., es aplicable tanto al proceso administrativo ordinario como al de lesividad, $y$, por lo tanto, no sólo los particulares, sino también la Administración, puede, apoyándose en aquel precepto, acudir a la jurisdicción contenciosoadministrativa.

b) Que los contratos, exactamente como los actos administra-

(13) Ob. cit., pág. 345.

(14) El proceso administrativo de lesividad, cit., págs. 112 y ss. 
tivos, pueden vulnerar el derecho y los intereses de la Administración, por lo que nada impide que ésta intente destruir sus efectos mediante la oportuna demanda de lesividad.

c) Que es inadmisible la doctrina del Tribunal Supremo, según la cual los contratos administrativos no pueden declararse lesivos, pero sí puede la Administración rescindirlos o pedir la correspondiente declaración de nulidad, y es inadmisible, porque:

$\left.a^{\prime}\right)$ Los supuestos en que la Administración acude al proceso de lesividad son distintos a los de la rescisión; cuando la Administración provoca un proceso de lesividad no funda su pretensión en que el demandado, la otra parte contratante, haya incumplido sus obligaciones, sino sencillamente que al contratar infringió el Derecho.

b') Porque la nulidad debe pedirse a través de un proceso de lesividad, como había afirmado Albi.

d) Que el necho de que el contrato sea un acto bilateral, lejos de suponer un obstáculo a la tesis de su impugnabilidad a través de un proceso de lesividad, la refuerza, pues teniendo el contratista ciertos derechos dimanados del contrato, no le pueden ser desconocidos y no le queda otro camino a la Administración que el proceso de lesividad para que se declare su nulidad.

e) Que más que el contrato, "lo que declara lesivo la Administración es su declaración de voluntad, es decir, el acto o acuerdo mediante el cual otorgó sú consentimienton.

\section{Apreciación CRf́tica}

A) Del tenor literal del artículo $5 .^{\circ}$, L. C., se desprende que lo que en el mismo se admite es que, ante la jurisdicción conten: cioso-administrativa, se discutan las cuestiones "referentes al cumplimiento, inteligencia, rescisión y efectos de los contratos celebrados por la Administraciónn. Y en todos estos supuestos, en principio, la Administración, en virtud del privilegio de la acción directa puede dictar actos ejecutivos, que obligan al particular, sin perju:cio de que éste pueda acudir a los Tribunales para impugnar aquellos actos administrativos. Es decir, normalmente, en estos su- 
puestos contractuales, existe siempre un acto concreto que impugnar, una resolución de la Administración, que ésta puede haber adoptado de oficio o a instancia del particular, que ha acudido a la Administración antes de deducir su pretensión ante los Tribunales.

B) Ahora bien, ¿en qué supuestos cabe concebir que la Administración tenga que acudir, como demandante, a un proceso en materia contractual? No hemos de olvidar nunca que el proceso de lesividad es aquel que tiene por objeto pretensiones deducidas por una entidad administrativa para impugnar un acto de la misma. Esto admitido, es necesario afirmar que los supuestos en los que la Administración tendrá que acudir a un proceso de lesividad serán mínimos, pues como goza del privilegio de la acción directa, en materia de cumplimiento, intepretación y rescisión de los contratos, podrá dictar actos ejecutivos sin que el particular tenga otro recurso que el de acudir a la vía contenciosa a defender sus derechos. Es decir, en principio la Administración goza de medios en vía administrativa que hacen que no le sea imprescindible acudir a un proceso de lesividad; los derechos que tiene ef particular como consecuencia del contrato administrativo no pueden ser puestos a la facultad de la Administración. Sin embargo, existen supuestos en que la Administración puede tener necesidat de acudir a un proceso administrativo como demandante, y al pretender la revocación o anulación de uno de sus actos, debe hacerlo a través de los trámites de un proceso de lesividad. Estos supuestos, pueden reducirse a los siguientes:

1. Cuando la Administración, haciendo uso del privilegio de la acción directa que, indudablemente, tiene, dicta un acto que reconoce derechos en favor del particular. En estos casos, si la Administración desea privar de efectos al acto declaratorio de derechos, debe acudir al proceso de lesividad. Así, en una sentencia de 3 de febrero de 1906 se admite una pretensión de lesividad contra un acuerdo por el que se rescindió un contrato de arrendamicnto de arbitrios fijando una indemnización al contratista.

2. Cuando se da algún supuesto de nulidad del contrato. Ahora bien, en estos casos no se impugna directamente el contrato; 
lo que impugna la Administración (de análoga manera que el particular) (15) es: o el acto por el que se acude a una forma de contratación administrativa o el acto de adjudicación. Así, en una sentencia de 8 de mayo de 1936, se resolvió un "recurso" de lesividad dirigido contra un acuerdo de una Comisión permanente sabre concurso para construir una verja de unos jardines, señalando que cel recurso se acomodaba al procedimiento legal establecido para la pretendida finalidad", y en otra de 26 de octubre de 1921 se revocó una orden autorizando una adjudicación.

Jesús González Pérez, Registrador de la Propiedad

(15) Cfr. mi trabajo La declaración de lesividad, cit., pág. 69. 